\title{
Identification of Cryptosporidium from Dairy Cattle in Pahang, Malaysia
}

\author{
Nur Hazirah Hisamuddin', Najat Hashim', Sharmeen Nellisa Soffian', Mohd Hishammfariz Mohd Amin', \\ Ridhwan Abdul Wahab", ${ }^{1,2}$ Mardhiah Mohammad ${ }^{1,2}$, Muhammad Lokman Md Isa ${ }^{2,3}$, Afzan Mat Yusof ${ }^{1,2, *}$ \\ ${ }^{1}$ Department of Biomedical Science, Kulliyyah of Allied Health Sciences, International Islamic University of Malaysia, Jalan Sultan Ahmad Shah, \\ Bandar Indera Mahkota, 25200 Kuantan, Pahang, Malaysia; 'Integrated Cellular and Molecular Biology Cluster (iMolec), Integrated Centre for \\ Research Animal Care and Use, International Islamic University Malaysia, Jalan Sultan Ahmad Shah, Bandar Indera Mahkota, 25200 Kuantan, \\ Pahang, Malaysia; ${ }^{3}$ Department of Basic Medical Sciences, Kulliyyah of Nursing, International Islamic University Malaysia, Jalan Hospital Campus, \\ 25710 Kuantan, Pahang, Malaysia
}

\begin{abstract}
Cryptosporidium, a protozoan parasite, can cause cryptosporidiosis which is a gastrointestinal disease that can infect humans and livestock. Cattle are the most common livestock that can be infected with this protozoan. This study was carried out to determine the prevalence of Cryptosporidium infection in cattle in Kuantan, Pahang, Malaysia and to find out the association between the occurrence of infection and 3 different ages of cattle (calves less than 1 year, yearling, and adult cattle). The samples were processed by using formol-ether concentration technique and stained by modified Ziehl Neelsen. The results showed that $15.9 \%$ (24/151) of cattle were positive for Cryptosporidium oocysts. The occurrence of Cryptosporidium in calves less than 1 year was the highest with the percentage of $20.0 \%$ (11/55) followed by yearling and adult cattle, with the percentage occurrence of $15.6 \%(7 / 45)$ and $11.8 \%(6 / 51)$, respectively. There was no significant association between the occurrence and age of cattle and presence of diarrhea. Good management practices and proper hygiene management must be taken in order to reduce the infection. It is highly important to control the infection since infected cattle may serve as potential reservoirs of the infection to other animals and humans, especially animal handlers.
\end{abstract}

Key words: Cryptosporidium, cattle, age, Pahang, Malaysia

Cryptosporidium sp. is a protozoan parasite that can cause gastrointestinal infection known as cryptosporidiosis. This parasite is responsible for veterinary problems particularly enteric illness outbreaks in livestock animals [1]. In farm animals, cattle are recognized as the most common mammalian species that can be infected by Cryptosporidium [2-4]. It is known since 1980s that calves and cattle have been identified as an important reservoir for zoonotic Cryptosporidium spp. [5]. The major Cryptosporidium sp. that infects calves is Cryptosporidium parrum which can cause severe watery, yellowish, and foulsmelling acute diarrhea that may lead to morbidity and mortality [6].

In Malaysia, little is known about Cryptosporidium spp. infection in cattle especially in Kuantan, Pahang. The first report of

\footnotetext{
- Received 30 December 2015, revised 15 March 2016, accepted 30 March 2016.

*Corresponding author (afzan@iium.edu.my)

(c) 2016, Korean Society for Parasitology and Tropical Medicine

This is an Open Access article distributed under the terms of the Creative Commons Attribution Non-Commercial License (http://creativecommons.org/licenses/by-nc/3.0) which permits unrestricted non-commercial use, distribution, and reproduction in any medium, provided the original work is properly cited.
}

the incidence of $C$. parvum among calves in Malaysia was reported by Lee et al. [7] who found 4 out of 11 diarrheic calves in Johor had the infection. For more than a decade, there was no study done on Cryptosporidium in cattle in Malaysia until 2005. Farizawati et al. [8] reported that Cryptosporidium oocysts from cattle had contaminated rivers in Sungai Langat Basin, and Halim et al. [9] reported the first data on Cryptosporidium deer-like genotype from cattle in Selangor.

Since there are few studies on Cryptosporidium infection in cattle in Kuantan area, the present study attempted to identify the occurrence of Cryptosporidium in cattle and to find out the association of the occurrence with age groups of cattle and the presence of diarrhea.

This cross-sectional study was conducted at a dairy cattle farm $\left(3^{\circ} 43^{\prime} 01.7^{\prime \prime} \mathrm{N} 103^{\circ} 00^{\prime} 41.6^{\prime \prime E}\right)$ located in Ulu Lepar, Kuan$\tan$ Pahang, Malaysia (Fig. 1). Kuantan is located at east coast of Peninsular Malaysia, and the climate is tropical rainforest climate. The average maximum temperature is $31^{\circ} \mathrm{C}$, and the average minimum temperature is $23^{\circ} \mathrm{C}$ [10].

Ethical clearance was obtained from the Institutional Ani- 


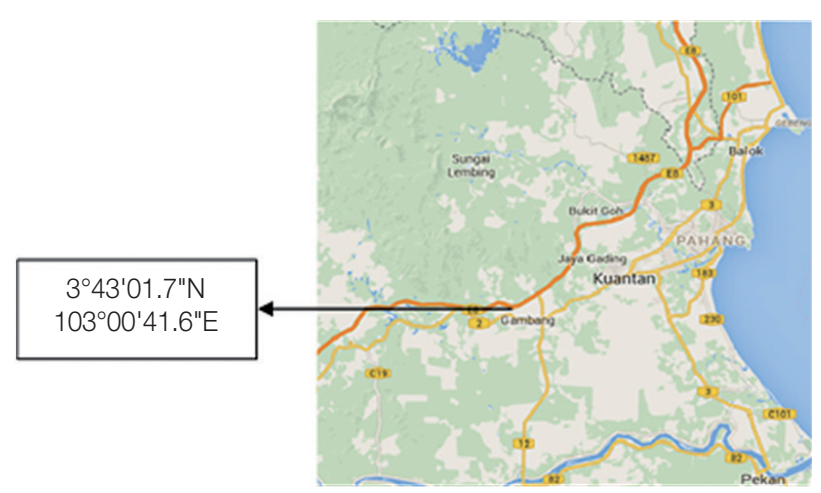

Fig. 1. The sampling site in Kuantan, Pahang, Malaysia.

mal Care and Use Committee (IACUC), International Islamic University of Malaysia (IIUM). A total of 151 fecal samples were collected between May 2015 and August 2015. The fecal samples were collected according to the age group; 55 samples from calves (less than 12 months), 45 samples from yearlings (12-24 months), and 51 samples from adults (more than 24 months). The fecal samples were collected directly from the rectum of the animals by using sterile plastic gloves. The samples were transferred into stool containers and preserved in $10 \%$ formalin. For each animal, the sampling date, age, identification tag, gender, and consistency of feces (score 0-1, 0: absence of diarrhea, 1: presence of diarrhea) were recorded. The samples were immediately transported to the laboratory and stored at $4^{\circ} \mathrm{C}$ before analysis.

The fecal samples were processed by using formol-ether concentration technique based on the method of Allen and Ridley [11] with slight modifications. Approximately $1 \mathrm{~g}$ of stool sample was emulsified in $4 \mathrm{ml}$ of $10 \%$ formal saline by using an applicator stick. The suspension was filtered through a sieve or gauze into a beaker. A 3-4 ml formal saline was added followed by an addition of $2.5 \mathrm{ml}$ diethyl ether to the formalized solution. The samples were centrifuged at $500 \mathrm{~g}$ for $30 \mathrm{sec}$ and continued with $500 \mathrm{~g}$ for another $20 \mathrm{sec}$. Finally, the supernatant was removed, and 1 or 2 drops of the resuspended pellet were smeared onto a microscope slide and stained with modified Ziehl Neelsen for Cryptosporidium examination. Later, the slides were air-dried and viewed under the $\mathrm{x}$ 1,000 objective lens of a light microscope.

Statistical analysis were performed by using Statistical Package for Social Sciences for windows SPSS (version 16). Chisquare test was used to compare the occurrence of infection between the age group of cattle, and Fisher's exact test was used to find the association between the occurrence of infec-
Table 1. The occurrence of Cryptosporidium in cattle in different age groups of cattle

\begin{tabular}{lcccc}
\hline Age & Total sample & Positive & Occurrence $(\%)$ & $P$-value \\
\hline Calves & 55 & 11 & 20 & \\
Yearling & 45 & 7 & 15.6 & 0.51 \\
Adult & 51 & 6 & 11.8 &
\end{tabular}

If $P$-value of less than 0.05 was considered statistically significant.

Table 2. The association between the presence of diarrhea and the occurrence of infection

\begin{tabular}{lcccc}
\hline Age & Total sample & Positive & Occurrence (\%) & $P$-value \\
\hline Diarrheic & 23 & 4 & 17.4 & 0.764 \\
Non-diarrheic & 128 & 20 & 15.6 & \\
\hline
\end{tabular}

$P$-value of less than 0.05 was considered statistically significant.

tion and the presence of diarrhea. A $P$-value of $<0.05$ was considered as the level of significance.

Referring to Table 1, the results showed that the prevalence of Cryptosporidium infection in calves less than 1 year was the highest compared to those in yearling and adult cattle. However, there was no significance difference $(P>0.05)$ between the age group and occurrence of Cryptosporidium. Analysis indicated that the occurrence of Cryptosporidium in calves less than 1 year was the highest with the percentage of $20.0 \%$ while in yearling and adult cattle, the percentage of occurrence was $15.6 \%$ and $11.8 \%$, respectively.

Of the total 151 samples collected, 23 were diarrheic samples, and 128 were non-diarrheic ones. As shown in Table 2, from 23 diarrheic samples, 4 (17.4\%) were positive for infection while out of 128 non-diarrheic samples, 20 (15.6\%) were positive for Cryptosporidium oocysts. However, the results showed that there is no significant difference between the presence of diarrhea and occurrence of infection.

Microscopic analysis of 151 fecal samples showed that 24 cattle (15.9\%) were positive for Cryptosporidium infection. Studies on Cryptosporidium infection in cattle population have been conducted from other researchers. The results were almost similar with former studies in Egypt, Poland, and China with the overall prevalence of $13.6 \%, 17.0 \%$, and $16.0 \%$, respectively [12-14]. So far, there were only 2 data collected from Pahang area which was done in Kuantan and Jerantut, Pahang. Yap et al. [15] reported a lower prevalence of Cryptosporidium infection in Kuantan and Jerantut areas, Pahang as compared to the present study which was $2.7 \%$ and $2.9 \%$, respectively. Another study conducted in Johor by Muhid et al. [16] reported that the overall prevalence of Cryptosporidium infection in 
pre-weaned and post-weaned calves was $27.1 \%$ (65/240) indicating a higher prevalence of infection compared to the present study. The dissimilarity in the prevalence among countries may be due to a different amount of stocking rate and different management system in the farm [17].

In summary, calves less than 1 year recorded the highest occurrence of Cryptosporidium sp. followed by yearlings and adult cattle. Similar high prevalences of Cryptosporidium in young calves compared to adult cattle have been reported by other studies [18-20]. This finding is most likely due to the low immune system function of young neonates as suggested by Maurya et al. [21]. Young animals have become more vulnerable to infection and disease, while infections in adults usually show no symptoms [22]. This result is in agreement with other studies which found no statistically significant association between infection and diarrhea [23-26]. On the other hand, other previous studies have reported that Cryptosporidium sp. infection is associated with the occurrence of diarrhea [27].

The present study has succeeded to achieve the objective of the research. This research has indicated that there is Cryptosporidium infection in cattle in Kuantan, Pahang. The findings suggested that control and prevention measures must be taken in order to reduce the infection among cattle. It is highly important to control the infection since cattle infected with parasites may serve as potential reservoirs of the infection to other animals and humans especially animal handlers. Good management practices and proper hygiene managements are the most effective weapons to combat Cryptosporidium spp. infections.

\section{ACKNOWLEDGMENTS}

This study was funded by RAGS grant no. 13-010-0073. The authors are highly grateful to the management and technical staff of Department of Veterinary Services, Kuantan Malaysia for their kind cooperation during the study period. The technical assistance from laboratory assistance of Kulliyyah of Allied Health Science and Integrated Centre for Research Animal Care and Use (ICRACU) are highly appreciated. We would also express our gratitude to the respective farmers for the cooperation during this study.

\section{CONFLICT OF INTEREST}

We declare that we have no conflict of interest.

\section{REFERENCES}

1. Gormley FJ, Little CL, Chalmers RM, Rawal N, Adak GK. Zoonotic cryptosporidiosis from petting farms, England and Wales, 1992-2009. Emerg Infect Dis 2011; 17: 151-152.

2. Zhang W, Wang R, Yang F, Zhang L, Cao J. Distribution and genetic characterizations of Cryptosporidium spp. in pre-weaned dairy calves in northeastern China's Heilongjiang Province. PLoS One 2013; 8: e54857.

3. Cui Z, Wang R, Huang J, Wang H, Zhao J, Luo N, Li J, Zhang Z, Zhang L. Cryptosporidiosis caused by Cryptosporidium parvum subtype IIdA15G1 at a dairy farm in northwestern China. Parasit Vectors 2014; 7: 529.

4. Huang J, Yue D, Qi M, Wang R, Zhao J, Li J, Shi K, Wang M, Zhang L. Prevalence and molecular characterization of Cryptosporidium spp. and Giardia duodenalis in dairy cattle in Ningxia, northwestern China. Vet Res 2014; 10: 292.

5. Izadi M, Jonaidi-Jafari N, Saburi A, Eyni H, Rezaiemanesh MR, Ranjbar R. Cryptosporidiosis in Iranian farm workers and their household members: a hypothesis about possible zoonotic transmission. J Trop Med 2014; Article ID 405875.

6. Lendner M, Daugschies A. Cryptosporidium infections: molecular advances. Parasitology 2014; 141: 1511-1532.

7. Lee CC, Sheik-Omar AR, Rasool N. Finding of Cryptosporidium parvum oocysts in diarrhoeic calves in Malaysia. Trop Biomed 1989; 6: 145-146.

8. Farizawati S, Lim YA, Ahmad RA, Fatimah CT NI, Siti-Nor Y. Contribution of cattle farms towards river contamination with Giardia cysts and Cryptosporidium oocysts in Sungai Langat Basin. Trop Biomed 2005; 22: 89-98.

9. Halim NA, Plutzer J, Bakheit MA, Karanis P. First report of Cryptosporidium deer-like genotype in Malaysian cattle. Vet Parasitol 2008; 152: 325-329.

10. Malaysian Meteorological Department. General Climate of Malaysia. Retrieved on 12 May 2014 (from http://www.met.gov.my).

11. Allen AVH, Ridley DS. Further observations on the formol-ether concentration technique for faecal parasites. J Clin Pathol 1970; 23: 545-546.

12. Amer S, Zidan S, Adamu H, Ye J, Roellig D, Xiao L, Feng Y. Prevalence and characterization of Cryptosporidium spp. in dairy cattle in Nile River delta provinces, Egypt. Exp Parasitol 2013; 135: 518-523.

13. Rzeżutka A, Kaupke A. Occurrence and molecular identification of Cryptosporidium species isolated from cattle in Poland. Vet Parasitol 2013; 196: 301-306.

14. Qi M, Wang H, Jing B, Wang D, Wang R, Zhang L. Occurrence and molecular identification of Cryptosporidium spp. in dairy calves in Xinjiang, northwestern China. Vet Parasitol 2015; 212: 404-407.

15. Yap NJ, Koehler AV, Ebner J, Tan TK, Lim YAL, Gasser RB. Molecular analysis of Cryptosporidium from cattle from five states of Peninsular Malaysia. Mol Cell Probes 2016; 30: 39-43.

16. Muhid A, Robertson I, Ng J, Ryan U. Prevalence of and manage- 
ment factors contributing to Cryptosporidium sp. infection in preweaned and post-weaned calves in Johor, Malaysia. Exp Parasitol 2011; 127: 534-538.

17. Regassa A, Gizaw O, Abunna F, Abebe R, Beyene D, Megersa B, Debela E, Asmare K, Skierve E. Cryptosporidium in calves, lambs and kids at Haramaya, eastern Ethiopia. Ethiop Vet J 2013; 17: 81-94.

18. Santín M, Trout JM, Fayer R. A longitudinal study of cryptosporidiosis in dairy cattle from birth to 2 years of age. Vet Parasitol 2008; 155: 15-23.

19. Al-Zubaidi, MTHS. Prevalence of some Cryptosporidium species in cattle in Baghdad, Iraq. AL-Qadisiya J Vet Med Sci 2012; 11 (qu.edu.iq).

20. Ouchene N, Ouchene-Khelifi NA, Zeroual F, Benakhla A, Adjou K. Study of Giardia spp., Cryptosporidium spp. and Eimeria spp. infections in dairy cattle in Algeria. J Parasitol Vector Biol 2014; 6: 61-65.

21. Maurya PS, Rakesh RL, Pradeep B, Kumar S, Kundu K, Garg R, Ram H, Kumar A, Banerjee PS. Prevalence and risk factors associated with Cryptosporidium spp. infection in young domestic livestock in India. Trop Anim Health Prod 2013; 45: 941-946.
22. O'Donoghue PJ. Cryptosporidium and cryptosporidiosis in man and animals. Int J Parasitol 1995; 25: 139-195.

23. Silverlås C, Emanuelson U, de Verdier K, Björkman C. Prevalence and associated management factors of Cryptosporidium shedding in 50 Swedish dairy herds. Prev Vet Med 2009; 90: 242-253.

24. Maikai BV, Umoh JU, Kwaga JK, Lawal IA, Maikai VA, Cama V, Xiao L. Molecular characterization of Cryptosporidium spp. in native breeds of cattle in Kaduna State, Nigeria. Vet Parasitol 2011; 178: 241-245.

25. Faleke OO, Yabo YA, Olaleye AO, Dabai YU, Ibitoye EB. Point prevalence of Cryptosporidium oocyst in calves grazing along River Rima Bank in Sokoto Nigeria. Pak J Biol Sci 2014; 17: 443446.

26. Azami M. Prevalence of Cryptosporidium infection in cattle in Isfahan, Iran. J Eukaryot Microbiol 2007; 54: 100-102.

27. Jafari R, Maghsood AH, Fallah M. Prevalence of Cryptosporidium infection among livestock and humans in contact with livestock in Hamadan District, Iran, 2012. J Res Health Sci 2013; 13: 8689. 